\title{
Computational Analysis of the Slope Stability of Flood Prevention and Bank Protection Engineering
}

\author{
Zhou Wu, Liu Zhijun, and Tang Lifang
}

\begin{abstract}
The flood prevention and bank protection engineering is the water retaining structure and there are large water head difference between the internal and external river levee. The seepage of river levee will affect the stability of the slope. The stability analysis of soil slope is an important content of the engineering design of flood prevention. On the basis of the data of geological survey and hydrometeorology, it applied the hydro-meteorological, geological and material parameters, with sweden slice method and the calculation of typical section, the stability calculation results of flood prevention and bank protection were simulated under different working condition, which had great guiding significance for the engineering design of flood prevention and bank protection.
\end{abstract}

Index Terms-Flood prevention, bank protection, slope stability.

\section{INTRODUCTION}

Watercourse is the channel for the drainage of flood, the engineering of flood prevention and bank protections are the protective screen for flood prevention, the watercourse is the natural slope, under the influences of water flow, sand, soil and human factors, the bank slope usually become unstable and suffer erosion. The bank slope maybe collapsed and become dangerous project that endanger the safety of slope protection and flood prevention.

Bank protection engineering refers to any constructions that protects the river bank directly or indirectly and remains the available regulation line, which includes the continuous and non-continuous bank protection engineering such as spur dike that was constructed with concrete, stone or other materials for changing or adjusting the river channel. The engineering of bank protection not only control and stabilize the river regime, adjust unfavorable river regime, stabilize the water front but also beneficial to the establishment of benign fairway, port and fine water environment. Therefore, the engineering of bank protection is not only an important part of channel improvement, but also the embankment engineering. Thus, the stability analysis of slope is an important content of the flood prevention's engineering design.

\section{A. Method of Slope Stability Analysis}

Slices method is a relatively simple and practical method for the stability analysis of viscous soil slope. In this method, it assumes the server possible shearing surface --slip surface, and divide the soil above the slip surface into several vertical

Manuscript received July 12, 2014; revised October 28, 2014.

The authors are with the Changjiang River Scientific Research Institute, Wuhan, China (e-mail: zhouwu120712@sina.com). soil stripe, it made an equilibrium analysis of force and moment of force on each soil stripe and obtained the security coefficient of soil stability under the condition of ultimate equilibrium, through a certain amount of trials, the location and corresponding (lowest) security coefficient of the most dangerous slip surface were found. Because the stability of soil slope is higher statically indeterminate issue, different kinds of simplified assumption must be made to reduce the unknown quantity. The calculated results must be made since different assumption and methods are used.

\section{B. Sweden Slice Method}

Sweden slice method divides the soil mass above the assumed sliding surface as $n$ vertical soil stripes to analyze the force and moment balance on each soil strip. This is the simplest method as it ignored the effect of interaction force among soil stripes.

When we are taking the computational analysis according to the overall moment balance condition of the sliding soil mass, the counter-force distribution of the entire sliding cambered surface is unclear because the slope on each point of the sliding surface are different and the normal and tangential effect force on the cambered surface, such as external load is hard to be calculated. Besides, for viscous soil slope as $\Phi>0$, particularly when the soil slope is constitute of multilayer and it will be difficult to obtain the size and centre-of-gravity position. Therefore, in the stability analysis of slopes, for the convenience of calculating the weight of soil mass and shearing strength more accurate, the sliding soil mass is divided into several vertical soil stripes, to calculate resisting moment and sliding moment, take their sum and calculate the security coefficient, this is the basic principle of slices method. This method also assumes each soil strip as body of invariant rigidity and won't consider the acting force between sides of the soil.

\section{Bishop Method}

The connotation that Bishop Method have proposed about the stability coefficient of soil slope is the ratio of shearing strength $t f$ of the entire sliding soil and the actual shearing strength $T$ generated, that is $K=t f \div t$, it have taken the existing acting force of each side of soil stripe, the basic principle and methods are as follows:

Suppose the sliding surface is a slip circle with center of a circle as $O$ and radius as $R$, take any soil strap i as detached body, the surrounding applied force of the detached body is: tangential force $\mathrm{Ti}$ and normal reaction $\mathrm{Ni}$ generated by the weight of soil stripe $W i$ that respectively acted on the center of underside. The normal reaction and tangential force of the soil stripe respectively are $E i, E i+1$ and $X i, X_{1}+i$.

\section{Method Comparison}

Sweden slice method and bishop method can meet the 
requirement of polygonal closing conditions without considering the tangential force among strips. That is to say, it contains the horizontal force among stripes, although the horizontal force isn't presented in the formula, its features are as follows:

Meet the condition of overall moment balance;

Meet the polygonal closing conditions among different soil stick but not the moment balance condition of soil slices.

Suppose normal force is the only force among slices, without tangential force;

Meet the condition of limit balance; bishop method has considered the effect of horizontal force among slices, the obtained security coefficient is higher than Sweden slice method.

TABLE I: INDEX USED IN THE STABILITY CALCULATION OF REVETMENT BODY

\begin{tabular}{|c|c|c|c|c|c|c|}
\hline \multirow{3}{*}{ Material } & \multirow{3}{*}{$\begin{array}{l}\text { Gravity } \\
\left(\mathrm{g} / \mathrm{cm}^{3}\right)\end{array}$} & \multirow{3}{*}{$\begin{array}{c}\text { Saturated unit } \\
\text { weight }\left(\mathrm{g} / \mathrm{cm}^{3}\right)\end{array}$} & \multicolumn{2}{|c|}{ Shearing strength } & \multirow{3}{*}{ Friction coefficient } & \multirow{3}{*}{$\begin{array}{l}\text { Values of ground bearing } \\
\text { capacity }(\mathrm{kPa})\end{array}$} \\
\hline & & & \multirow{2}{*}{ 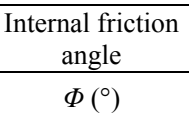 } & \multirow{2}{*}{$\begin{array}{l}\text { Cohesion } \\
C(\mathrm{kPa})\end{array}$} & & \\
\hline & & & & & & \\
\hline Sandy soil & 17.82 & & 26.02 & 11.7 & 0.3 & 100 \\
\hline land pebble & 19.5 & 20.1 & 28 & 18 & 0.35 & 450 \\
\hline Artificial filling soil & 19.5 & 20 & 30 & 0 & 0.2 & \\
\hline $\begin{array}{l}\text { intense weathered } \\
\text { mudstone }\end{array}$ & 24.9 & & & & 0.3 & 300 \\
\hline $\begin{array}{c}\text { weak weathered } \\
\text { mudstone }\end{array}$ & 25.4 & & & & 0.4 & 1200 \\
\hline $\begin{array}{l}\text { intense weathered } \\
\text { sandstone }\end{array}$ & 24.4 & & & & 0.35 & 450 \\
\hline $\begin{array}{l}\text { weak weathered } \\
\text { sandstone }\end{array}$ & 24.9 & & & & 0.5 & 5000 \\
\hline
\end{tabular}

TABLE II: INDEX USED IN THE STABILITY CALCULATION OF REVETMENT BODY

\begin{tabular}{|c|c|c|c|c|c|c|}
\hline \multirow[t]{2}{*}{ Name of Soil Layer } & \multirow{2}{*}{$\begin{array}{l}\text { Natural weight } \\
\qquad\left(\mathrm{g} / \mathrm{cm}^{3}\right)\end{array}$} & \multicolumn{2}{|c|}{$\begin{array}{c}\text { Natural shearing } \\
\text { strength }\end{array}$} & \multicolumn{2}{|c|}{ saturated shearing strength } & \multirow{2}{*}{$\begin{array}{l}\text { osmotic coefficient } \\
\qquad(\mathrm{cm} / \mathrm{s})\end{array}$} \\
\hline & & $\Phi\left(^{\circ}\right)$ & C (kpa) & $\Phi\left(^{\circ}\right)$ & C (kpa) & \\
\hline Filler of earth and stone & 18.1 & 28 & 10 & 25 & 6 & $7 \times 10^{-2}$ \\
\hline back filled region of sandy gravel & 19.11 & 33 & 0 & 31 & 0 & $2 \times 10^{-2}$ \\
\hline Sandy soil & 16.85 & 24 & 11.7 & 20 & 7 & $11 \times 10^{-4}$ \\
\hline $\begin{array}{l}\text { back filled region of riprap } \\
\text { (building sandstones) }\end{array}$ & 20 & 34 & 0 & 30 & 0 & $2 \times 10^{-2}$ \\
\hline land pebble & 17.82 & 28 & 12 & 25 & 7 & \\
\hline intense weathered sandstones & 24.4 & 26.6 & 400 & 23 & 200 & \\
\hline Weak weathered sandstones & 24.9 & 35.5 & 700 & 32 & 500 & \\
\hline intense weathered mudstone & 24.9 & 30 & 0 & 28 & 0 & \\
\hline Weak weathered mudstone & 25.4 & 32 & 500 & 29 & 300 & \\
\hline
\end{tabular}

TABLE III: OUTCOME TABLE OF THE STABILITY CALCULATION OF SLOPE

\begin{tabular}{c|c|c|c|c}
\hline \multicolumn{2}{c}{ Calculation of Working Condition } & typical Section I & typical Section II & available safety factor \\
\hline \multirow{4}{*}{\begin{tabular}{c} 
Normal use \\
\cline { 2 - 5 }
\end{tabular}} & Design flood period & 1.245 & 1.240 & - \\
\cline { 2 - 5 } & Unfavorable medium water level & 1.234 & 1.154 & - \\
\cline { 2 - 5 } & low water level & 1.176 & 1.179 & - \\
\hline $\begin{array}{c}\text { Abnormal } \\
\text { use }\end{array}$ & $\begin{array}{c}\text { construction period(including } \\
\text { time of completion) }\end{array}$ & 1.210 & 1.467 & - \\
\hline
\end{tabular}

\section{General Situation OF THE ENGINEERING}

The flood prevention and bank protection engineering on Shugang road of Naxi district in Sichuan is located between the warehouse of provincial shipping company in Naxi district, Lizhou, Sichuan and the right bank of Yangtze river of Daoliu river. The range of bank protection is from the end of Lutianhua coal wharf to the entrance of Daoliu River to Yangtze River and the length of channel segment is about $1.5 \mathrm{~km}$. It is mainly for protecting the life and property security of the residents along the river and the large and medium-sized enterprise and public institution, such as Lizhou Natural Gas and Chemical Industries Group Limited Company, Naxi Wood Forwarding Station, Naxi Dispatching Place of Chunan Forestation Branch, Naxi Wood Forwarding Station of Bulk Wharf of Shuguang Shipping Company, Sewage Treatment Plant etc.

The full length of dyke is 1329.87 meters, taking the downstream of Lutianhua coal wharf as the starting point, passing Toujuliang to the mouth of Daoliu river. The project's channel segment adopts the mode of dyke bottom + bank protection with slope. The maximum altitude of 
protective bank is $27.5 \mathrm{~m}$.

This engineering of flood prevention and bank protection is designed for a 20 years' flood standard according to the importance and relevant planning of the protected place. In accordance with the stipulations in the "Design Standards of Bank Protection Engineering" GB50286-98 and "Grading and Flood Standard of Water Resources and Hydropower Engineering" SL252-2000, the dike grade of key construction is 4, the grade of minor construction and temporary building are 5 [1]-[3].

\section{COMPUTATION PARAMETERS}

\section{A. Hydro-Meteorological Parameter}

The engineering reach belongs to south subtropical humid monsoon climate, Naixi district of Luzhou is part of the subtropical monsoon climate area, and it usually has heavy rain or rainstorm for the alternate influence of dry and cold air from the northern continent as well as the warm and humid monsoon from the south. According to the actual measurement statistics from Luzhou meteorological station, the average temperature is $17.5^{\circ} \mathrm{C}$ for ages, the extremely highest temperature is $39.7^{\circ} \mathrm{C}$ (September 6,1995 ), while the extremely lowest temperature is $-2.4^{\circ} \mathrm{C}$ (January 14,1963 ), the average annual precipitation is $1048.9 \mathrm{~mm}$ for years, the average annual evaporation capacity is $975.0 \mathrm{~mm}$, the average relative temperature is $84 \%$, the average sunshine duration is 1322.7 hours, the percentage of sunshine is $30 \%$, the annual average frost-free season for years is 350days, the average fog day annually for many years is 59.5 days, northwester is very usual for the whole year, the average wind velocity is $1.2 \mathrm{~m} / \mathrm{s}$, while the largest wind velocity is $15.0 \mathrm{~m} / \mathrm{s}$, the corresponding wind direction is NNW.

\section{B. Geological Parameter}

According to the report of "Engineering Geological Investigation of the flood prevention and bank protection on Shugang road, Naxi disctrict, Luzhou, Sichuan (detailed geological survey)", proposed value of each ground layer of the project is shown in Table I.

\section{Material Parameter}

Geological proposed value was calculated through physical mechanics and confirmed with similar engineering. The major calculating parameters were shown as Table II.

\section{Structural Computational Mechanics Model}

\section{A. Calculation Principle and Assumption}

Calculation principle: The typical section in the design section was calculated for the engineering calculation. Sweden slice method was used for the calculation, arc slide face method, water active force method are effective stress methods. The stability calculation uses the given circular entrance range to search the dangerous slip surface, the width of the soil stripe with slices method is $1.0 \mathrm{~m}$, the step length of centre in search is $1.0 \mathrm{~m}$, the entrance and exit step length in search is 1.0 also. Calculation hypothesis:
When the levee slope is in the most unfavorable status, the variation range of water level is the typical design flood level $\sim$ low water level, calculate the stability safety factor according to the steady seepage with the amplitude of variation as $1.0 \mathrm{~m}$. The water level corresponds to minimum safety factor as the most unfavorable water level [4].

The sidewalk load (uniform load $q=5 \mathrm{kN} / \mathrm{m}^{2}$ ) of 241.0 meters' elevation packway which has the width within $2.0 \mathrm{~m}$ and the width of levee crown within $8.0 \mathrm{~m}$ ), the car load (uniform load $q=15 \mathrm{kN} / \mathrm{m}^{2}$ ) on the range of $20 \mathrm{~m}$ of the rear levee crown [5].

\section{B. Section Calculation}

For different types of design section, this calculation used the section with the stake mark $0+343.410$ as the typical section.

\section{CAlculations of Working CONDition AND Results}

\section{A. Calculations of Working Condition}

According to the stipulation of "Design specifications of embankment project", the working condition calculation of work stability of slope under normal and enduring condition of this project is as following:

Working condition 1: Design the water side levee slope under the water level of flood;

Working condition 2: Design the water side levee slope in the period that water level fall suddenly (the calculation shall consider the design flood level decrease $3.0 \mathrm{~m}$ )

Working condition 3: The water side levee slope under the condition of unfavorable water level;

Working condition 4: The water side levee slope under low water level;

\section{B. Calculation Result}

The calculation result is shown in Table III. The calculation shows that the stability of slope can meet all requirements under different working conditions.

\section{CONCLUSION}

The engineering design uses the slope protection of dyke bottom + slope while the stability of bank slope is the key to the success of the engineering. The critical factors that affect the stability of bank slope are the intensity index of embankment's filler, the filler's compaction rate and the cleanup efforts of sand soil's covering etc. Therefore, the quality and technical requirements, intensity index, compaction requirement and relevant test requirement must be clarified in the design outcomes [6].

\section{REFERENCES}

[1] GB50201-94 Flood Control Standard, Beijing: China Planning Press, 1994.

[2] GB50286-98 Design Specifications of Dike Construction, Beijing: China Planning Press, 1998.

[3] SL252-2000 Grading and Flood Standard of Water Resources and Hydropower Engineering, Beijing: China Water Power Press, 2000.

[4] L. Maotian, L. Yong, and Y. Qing, "Discontinuous deformation computational mechanics model and its appliation in stability Analysis 
of rock slope," Chinese Journal of Rock Mechanics and Engineering, 2000, vol. 19, no. 3, pp. 289-294.

[5] G. S. Long, Y. Z. Yun, and C. Sitian, "Analyses on ground surface settlement due to extra-shallow-underground-pipe jacking with curve by stochastic mediun theory," Journal of Chong Qing Jiao Tong University, 2005, vol. 24, no. 6, pp. 99-103.

[6] G. X. Nan, Computer Analysis of Civil Engineering, Beijing: China Construcion Industry Press, 2000.

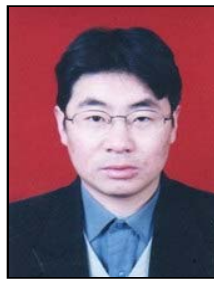

Zhou Wu was graduated from Department of Engineering Mechanics, Hehai university in 1996 and he obtained the bachelor degree. He worked in the Changjiang River Scientific Research Institute for dam safety monitoring, since 1996. In April, 1998, he was an expert in the study of soil engineering and seepage. He has been to Singapore for work and study, And then he returned to China in April, 2000 and acted as a deputy chief engineer in soil engineering department. Now, he hold the post of legal representative of the vice general manager and as a general manager in Wuhan Geo-Eng Yangtze Australia CO., Ltd.

He has attended and completed two projects of the national science and technology support, two social welfare projects in ministry of water resources, one project of national natural science funds. He published over ten academic papers, took part in the compiling and writing of 2 monographs, 2 industrial standards and obtained 3 national patents of the utility model. 